\title{
DESARROLLO Y VALIDACIÓN DE LA ESCALA DE RESPUESTAS PSICO- LÓGICAS DE DUELO ANTE LA PÉRDIDA DE LA SALUD (RPD-PS-38)
}

\author{
DEVELOPMENT AND VALIDATION OF THE SCALE OF PSYCHOLOGICAL RESPONSES \\ OF GRIEF BEFORE THE LOSS OF HEALTH (RPD-PS-38)
}

Melina Miaja Ávila y José Moral de la Rubia

Facultad de Psicología, Universidad Autónoma de Nuevo León. México

Resumen

Antecedentes: Un estudio cualitativo propuso una escala para evaluar las 5 fases del duelo ante la pérdida de la salud, la escala FD-66. Otro estudio cuantitativo contrastó el modelo de Kübler-Ross en el que se basa la escala FD-66; definió cada fase como escalas unidimensionales, empleando 39 ítems de la escala FD-66, refutó el modelo secuencial y propuso contratar un modelo de 6 factores correlacionados, incluyendo 4 ítems ignorados en el análisis.

Objetivos: 1) determinar la estructura factorial de la escala FD-66 reducida a 43 ítems, 2) calcular la consistencia interna de los factores, 3) describir la forma de la distribución de los factores, 4) describir la frecuencia de expresión de las respuestas de duelo, y 5) calcular y comparar los promedios de los factores.

Método: Se aplicó la escala FD-66 a una muestra no probabilística de 120 mujeres mexicanas con cáncer.

Resultados: La escala quedó reducida a 38 ítems, presentó una estructura de seis factores de primer orden correlacionados (negación, ira, promesas/negociación, fe/esperanza, depresión y aceptación), y dos factores de segundo orden independientes (reacción de afecto negativo y actitud positiva ante la enfermedad), conforme con la hipótesis. Las consistencias internas de los factores fueron altas y sus distribuciones no se ajustaron a una curva

\section{Abstract}

Background: A qualitative study proposed a scale to assess the 5 phases of grief before the loss of health, the FD-66 scale. Another quantitative study contrasted the Kübler-Ross model in which the FD-66 scale is based. This quantitative study defined each phase of grief by means of one-factor scales, using 39 of 66 items composing the FD-66 scale, refuted the Kübler-Ross sequential model, and suggested contrasting a correlated 6-factors model (including 4 items ignored in the analysis).

Objectives: 1) to determine the factor structure of the FD-66 scale reduced to 43 items, 2) calculate the internal consistency of the factors, 3) describe the shape of the distribution of the factors, 4) describe the frequency of expression of grief responses, and 5) calculate and compare the means of the factors.

Method: The FD-66 scale was applied to a non-probability sample of 120 Mexican women with cancer.

Results: The scale was reduced to 38 items, presented a structure of correlated six first-order factors (denial, anger, promises/ negotiation, faith/hope, depression, and acceptance), and independent two secondorder factors (negative affect reaction, and positive attitude toward disease). These factor models were consistent with the hypothesis. The internal consistency of the factors was

Correspondencia:

Melina Miaja Ávila

Dr. Carlos Canseco 110. Col. Mitras Centro. Monterrey, NL, México. Tel. 8183338233. Ext. 423. Fax. Ext. 103.

E-mail: miajaam@live.com.mx 
normal. Las respuestas psicológicas más frecuentes fueron fe/esperanza y aceptación; las menos frecuentes ira, depresión y negación; e intermedia promesas/negociación.

Conclusiones: La escala de Respuestas Psicológicas de Duelo ante la Pérdida de la Salud (RPD-PDS-38) es fiable y válida. Se recomienda su uso y estudio.

Palabras clave: Duelo, cáncer, negación, ira, pacto-negociación, depresión, aceptación.

\section{INTRODUCCIÓN}

Las personas que tienen enfermedades crónicas, como el cáncer, pasan por un proceso de asimilación y acomodación. Debido a las transformaciones que la enfermedad y los tratamientos conllevan, esta acomodación implica la aceptación de diversas pérdidas, como la pérdida de salud, seguridad, autonomía, libertad ${ }^{(1)}$, ideal del futuro y lógica del vínculo con el otro ${ }^{(2)}$, entre otras pérdidas. A este proceso se le conoce como proceso de duelo ${ }^{(1)}$. Tizón ${ }^{(3)}$ define el proceso del duelo como un conjunto de fenómenos psicológicos, psicosociales e incluso económicos, que surgen ante cualquier tipo de pérdida (relacional, intrapersonal, material y evolutiva). La pérdida se refiere a lo que la persona trata de adaptarse $^{(4)}$. Por lo tanto, la función del proceso del duelo es elaborar el impacto de la pérdida y adaptarse a la nueva situación que se está viviendo ${ }^{(5)}$.

Gran parte de lo que sabemos sobre la respuesta humana ante la pérdida proviene de investigaciones realizadas en adultos que han perdido a un ser querido a través de la muerte ${ }^{(6-12)}$. Como consecuencia de esto, los instrumentos de medición están enfocados a este tipo de pérdida, como el Inventario de Experiencias de Duelo ${ }^{(13)}$ y el Inventario Texas Revisado de Duelo ${ }^{(14)}$. No high and its distributions were not adjusted to normal curve. The most frequent psychological responses were faith/hope and acceptance; lest frequent responses were anger, depression and denial; and intermediate one was promises/ negotiation.

Conclusions: The scale of Psychological Responses of Grief before Loss of Health (RPDPDS-38) is reliable and valid. Use and study is recommended.

Key words: Grief, cancer, denial, anger, bargaining, depression, acceptance. obstante, el proceso del duelo puede experimentarse no sólo en situaciones relacionadas con la muerte, sino ante cualquier tipo de pérdida significativa ${ }^{(3,4)}$.

Al no existir ninguna escala de fases del duelo enfocada a la situación de pérdida de salud por una enfermedad crónico-degenerativa, se ha propuesto una nueva, la escala de las Fases del Duelo de 66 ítems $\left(\right.$ FD-66) ${ }^{(15)}$. Los ítems de la escala FD-66 fueron redactados a partir de un estudio cualitativo y el modelo de las cinco fases del duelo de Kübler-Ross ${ }^{(16)}$. Se tomó este modelo debido a que en la actualidad es el más utilizado al estudiarse el proceso del duelo ante pérdidas significativas ${ }^{(9,17)}$.

El modelo de Kübler-Ross ${ }^{(16)}$ propone que las personas que se encuentran próximas a la muerte progresan a través de cinco fases para afrontar esta situación: negación, ira, negociación-pacto, depresión y aceptación, que estas cinco fases duran diferentes periodos de tiempo; y que se reemplazan unas a otras o coexisten a la vez.

La escala FD-66 ${ }^{(15)}$ permite conocer como los pacientes con cáncer están elaborando el proceso del duelo ante la pérdida de la salud. La importancia de conocer la elaboración del duelo radica en que dicho proceso puede tener consecuencias, ya sean positivas o negativas, en 
el ámbito biopsicosocial de los pacientes con cáncer. Por ejemplo, la negación ante la enfermedad repercute en el retraso de la búsqueda de tratamiento médico, en la falta de adherencia al tratamiento y en la ausencia de obtención de información sobre la enfermedad ${ }^{(18,19,20)}$; la ira ante la enfermedad perturba el funcionamiento del sistema inmune, agrava el dolor e incrementa el riesgo de muerte ${ }^{(21)}$; el pacto o negociación con un Ser Supremo ante la enfermedad proporciona un sentido a la vida y existencia, da más fuerza ante la adversidad, promoviendo así una orientación positiva $^{(22,23)}$; la depresión ante la enfermedad predice una elevada mortalidad ${ }^{(24,25)}$, y por último, la aceptación permite vivir en paz y armonía con la enfermedad y genera un gran bienestar emocional ${ }^{(26)}$.

Moral y Miaja ${ }^{(27)}$ realizaron un primer análisis de la escala FD-66 para poner a prueba el modelo secuencial de KüblerRoss $^{(16)}$. En este estudio, los ítems propuestos para cada etapa fueron analizados por separado, buscando un modelo de un factor para cada una de las 5 fases con consistencia interna alta, buen ajuste a los datos y validez de contenido. En este proceso se eliminaron 27 ítems de la escala FD-66. El modelo secuencial tuvo mal ajuste a los datos, proponiéndose un modelo no secuencial alternativo. Los autores concluyen que las fases no siguen una secuencia fija, sino que constituyen respuestas psicológicas relacionadas. Por este motivo, sugirieron realizar un nuevo análisis factorial con los 39 ítems seleccionados. En este análisis se recomendaba incluir 4 ítems de un factor de fe/esperanza en la recuperación, el cual se definió desde los 12 ítems iniciales elaborados para evaluar negociación-pacto, pero que fue ignorado en el contraste del modelo secuencial de las 5 fases, al no ser definido como una fase de duelo por Kübler-Ross.

Considerando esta reducción a 43 ítems de la escala FD-66, que el modelo secuencial no se ajustó bien a los datos y que no se ha analizado el conjunto de 43 ítems (incluidos los 4 de fe/esperanza), los objetivos del estudio fueron: 1) determinar la estructura factorial de la escala FD reducida a 43 ítems, 2) calcular la consistencia interna de los factores, 3) describir la forma de la distribución de los factores, 4) describir la frecuencia de expresión de las respuestas de duelo evaluadas, y 5) calcular y comparar los promedios de los factores. De este estudio surge una escala de respuestas psicológicas de duelo ante la pérdida de la salud que permite el estudio de factores de riesgo y protección para dichas respuestas.

Se formularon como hipótesis: 1) una estructura de seis factores correlacionados: negación, ira, promesas/negociación con un Ser Supremo, fe/esperanza en la recuperación, depresión y aceptación ${ }^{(27) ; 2) ~ c o n-~}$ sistencia interna alta en los seis factores ${ }^{(27)}$; 3) distribuciones de los factores con ajuste a una curva normal, al tratarse de una población clínica en proceso de adaptación a la enfermedad, cuando en una población general se esperaría una asimetría positiva al estar pocas personas afectadas por una situación de enfermedad crónica ${ }^{(28)}$, 4) frecuencias de expresión bajas en ira, depresión y negación, pero altas en aceptación, promesas/negociación con un Ser Supremo, fe/esperanza en la recuperación, al estudiarse una muestra con más de un año transcurrido desde el diagnóstico ${ }^{(9,29-31)}$ y 5) promedios significativamente mayores en aceptación, promesas/negociación, fe/ esperanza que en ira, depresión y negación por la razón argumentada en la cuarta hipótesis ${ }^{(9,29,30,31)}$.

\section{MÉTODO}

\section{Participantes}

Los criterios de inclusión para la muestra fueron: tener una enfermedad oncológi- 
ca diagnosticada, recibir tratamiento médico, tener al menos 15 años de edad, saber leer y escribir y firmar el consentimiento informado. Los criterios de exclusión fueron: tener fatiga excesiva que dificultase la atención.

La muestra quedó configurada por 120 mujeres. El 2,5\% (3 de 120) de las mujeres entrevistadas tenían entre $15 \mathrm{y}$ 19 años de edad (adolescentes), 14,2\% (17) entre 20 y 39 años (adultos jóvenes), $48,3 \%$ (58) entre 40 y 59 años (adultos de mediana edad) y 35\% (42) entre 60 y 78 años (adultos mayores). La media de edad fue 51,84 años (DT=13,63). El 63\% (76 de 120) de las mujeres encuestadas dijeron estar casadas, $17 \%$ (20 de 120) solteras, $8 \%$ (10 de 120 ) viudas, $7 \%$ (8 de 120) separadas y 5\% (6 de 120) en unión libre. La escolaridad varió de saber leer y escribir a estudios de posgrado terminados. La mediana de escolaridad correspondió a secundaria terminada y el valor modal a primaria terminada $(24 \%)$. La mediana de ingresos económicos familiares al mes correspondió al intervalo de 3.000 a 5.999 pesos mexicanos (aproximadamente de 250 a 499 dólares estadounidenses) y la media correspondió al intervalo de 6.000 a 11.999 pesos mexicanos (aproximadamente de 500 a 1.000 dólares estadounidenses).

El 50\% (60 de 120) de los casos fueron cáncer de mama, 15,8\% (19 de 120) cáncer cervicouterino, 11,7\% (14 de 120) cáncer en el sistema digestivo (colon, esófago y estómago), 7,5\% (9 de 120) cáncer de huesos o articulaciones (sarcoma), 5\% (6 de 120) cáncer de riñón, 3,3\% (4 de 120) cáncer en glándulas endocrinas (ovarios y tiroides), 2,5\% (3 de 120) linfomas, $1,7 \%$ (2 de 120) melanoma, 1,7\% (2 de 120) leucemia y $0,8 \%$ (1 de 120) cáncer cerebral. La media del tiempo transcurrido desde el diagnóstico de cáncer fue de 1 año y 5 meses (DT=2,02). El 48,3\% (58 de 120) indicaron estar recibiendo tratamien- to oncológico de radioterapia, 45,8\% (55) quimioterapia, 4,2\% (5) cirugía y 1,7\% (2) hormonal.

\section{Instrumento}

Escala de las Fases del Duelo (FD-66) ${ }^{(15)}$. La escala FD-66 fue creada a partir de un enfoque teórico desde la formulación original de Kübler-Ross ${ }^{(16)}$ y a partir de un enfoque empírico sensible a la cultura, utilizando la técnica de redes semánticas naturales. La escala FD-66 está integrada por 66 ítems. Éstos fueron redactados de manera directa; es decir que a mayor puntuación, mayor es la frecuencia con la que se experimentan cada una de las cinco fases del duelo ante la pérdida de la salud. El rango de respuesta de los 66 ítems tipo Likert fue fijado en cinco puntos (de $1=$ "nunca" a 5 = "siempre") $)^{(15)}$.

Moral y Miaja ${ }^{(27)}$ eliminaron 27 de los 66 ítems de la escala FD-66, buscando un factor general para cada una de las 5 fases de duelo. Los reactivos eliminados fueron: ítems 1, 2, 7, 11, 13, 14, 16, 18, 20, 23, $25,26,30,32,33,35,37,39,40,42,47$, 49, 54, 56, 57, 63 y 66. De este modo, la escala quedó reducida a 39 ítems. Las fases de negación, aceptación y depresión sí se definieron como unidimensionales, pero las otras dos fases fueron bidimensionales: pacto se dividió en promesas/ negociación con un Ser Supremo y Fe/esperanza. Ira se dividió en ira general e ira hacia objetos específicos. Por motivos de ajuste, consistencia interna y validez de contenido se desecharon los factores de fe/esperanza e ira generalizada en el contraste del modelo secuencial de 5 fases del duelo de Kübler-Ross.

Considerando la numeración de ítems originales de la escala FD-66 de Miaja y Moral(15), los 7 factores definidos fueron: negación con 8 indicadores (ítems 6, 15, $45,50,55,60,62$ y 64) y consistencia interna alta $(\alpha=0,74)$, ira generalizada con 3 
indicadores (ítems 2, 7 y 11) y consistencia interna alta $(\alpha=0,82)$, ira hacia objetos específicos con 6 indicadores $(21,31,36$, 41,46 y 51) y consistencia interna alta $(\alpha=0,82)$, promesas/negociación con un Ser Supremo con 7 indicadores (ítems 3, 8, $12,17,22,27$, y 52) y consistencia interna alta $(\alpha=0,83)$, fe/esperanza con 4 indicadores (ítems 32, 37, 42 y 57) y consistencia interna alta $(\alpha=0,80)$, depresión con 8 indicadores (ítems 4, 9, 28, 38, 43, 48, 53 y 58) y consistencia interna alta $(\alpha=0,76)$, aceptación de la enfermedad con 10 indicadores (ítems 5, 10, 19, 24, 29, 34, 44, 59, 61 y 65) y consistencia interna alta $(\alpha=0,85)^{(27)}$.

En el presente estudio, se desecharon los 3 ítems de ira generalizada debido a que no aportaban información adicional al factor de ira hacia objetos específicos que tuvo mayor validez de contenido y se mantuvieron los 4 ítems del factor de fe/ esperanza en la recuperación, como aconsejaron Moral y Miaja ${ }^{(27)}$. Así, el número de ítems inicialmente analizados fue 43.

\section{Procedimiento}

Se utilizó un muestreo no probabilístico de tipo intencional. Antes de comenzar el estudio se proporcionó el protocolo de investigación a las instituciones anfitrionas con la finalidad de obtener las aprobaciones por las autoridades para llevar a cabo el proyecto de investigación conforme a las normas éticas de Sociedad Mexicana de Psicología ${ }^{(32)}$.

La muestra se extrajo de siete lugares diferentes. El 69\% (83 de 120) de las pacientes fueron entrevistadas en tres albergues (Cruz Rosa, A.B.P., Desafío del Noreste, A.C., y Posada del Peregrino de Caritas de Monterrey, A.B.P.), 26\% (31) en dos clínicas (Clínica 0-19 y Opción Oncología), y 5\% (6) en dos grupos de autoayuda (Asociación Mexicana Contra el Cáncer de Mama, A.C. de la Fundación CIM*ab y el grupo Mujeres con Cáncer).
Para la administración del instrumento de medición se les pidió a las pacientes firmar la carta de consentimiento informado. En las menores de edad, la carta de consentimiento informado fue firmada por el cuidador primario (mayor de edad) y por la misma paciente conforme a las normas éticas de Sociedad Mexicana de Psicología ${ }^{(32)}$. Las participantes que aceptaron formar parte del estudio respondieron por escrito al instrumento en presencia de la entrevistadora, en salas polivalentes, cuartos, pasillos o diversos lugares permitidos por cada una de las instituciones donde se llevó a cabo el estudio. La muestra se recolectó de marzo a octubre del 2013.

\section{Análisis de los datos}

Se determinó la estructura factorial de los 43 ítems seleccionados ${ }^{(27)}$, empleando análisis factorial exploratorio (AFE) y confirmatorio (AFC). En el AFE, los factores se extrajeron por el método de ejes principales y la matriz de factores se rotó por el método Oblimin directo. El número de factores de primer orden se fijó por el criterio de Horn (autovalores observados por encima del punto de intersección entre la curva de sedimentación observada y la correspondiente al percentil 95 de 100 curvas procedentes de 100 muestras generadas al azar con el mismo número de casos y variables con distribución normal). Se eliminaron los ítems con cargas factoriales menores que 0,30 en la matriz de configuraciones y aquéllos con su carga factorial más alta en un factor no esperado. El número de factores de segundo orden se determinó por el criterio de Kaiser (autovalores mayores que 1). Las puntuaciones de los factores de primer orden se obtuvieron por el método de regresión.

Tras los AFE se realizaron los AFC en la misma muestra para estimar el ajuste a los datos de los modelos (de primer y segundo orden), usando el método de máxi- 
ma verosimilitud. Debido a la dificultad de obtener estos casos clínicos se aplicó ambos análisis en la misma muestra, aunque hubiera sido mejor emplear una nueva muestra para el AFC.

Se estudió el cumplimiento del supuesto de normalidad multivariada a través de la curtosis multivariada de Mardia. Valores de su razón crítica ( $\mathrm{RC}$ ) entre - 2 y 2 reflejan cumplimiento del supuesto y entre -10 y -2 ó 2 y 10 ligero incumplimiento ${ }^{(33)}$. Debido al incumplimiento de este supuesto se usaron los procedimientos de muestreo repetitivo para la estimación de la significación de parámetros (método de percentiles libres de sesgo) y para el contraste global de la bondad de ajuste (prueba de muestreo repetitivo de Bollen-Stine).

Se consideraron once índices de ajus-

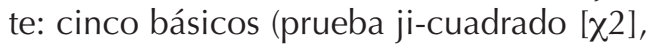
cociente entre el estadístico ji-cuadrado y sus grados de libertad $[\chi 2 / g l]$, función de discrepancia [FD], probabilidad de BollenStine y residuo estandarizado cuadrático medio [RMS SR]); dos poblacionales de no centralidad (parámetro de no centralidad poblacional [PNCP] y residuo cuadrático medio de aproximación [RMSEA] de Steiger-Lind); dos índices comparativos con el modelo nulo (índice de bondad de ajuste [GFI] de Jöreskog y Sörbom y su modalidad corregida [AGFI]) y dos índices comparativos con el modelo independiente (índice normado de ajuste [NFI] de Bentler-Bonett e índice comparativo de ajuste [CFI] de Bentler). Se consideraron como valores de buen ajuste para los índices: $p$ de $\chi 2$ y de la prueba de Bollen-Stine $>0,05, \chi 2 / g \mid \leq$ 2 , FD y $\mathrm{PNCP} \leq 1 / 4$ del valor correspondiente al modelo independiente, RMSEA y $\mathrm{RMS} S \mathrm{SR} \leq 0,05, \mathrm{GFI} \geq 0,95$ y AGFI, NFI y $\mathrm{CFI} \geq 0,90$; y como valores adecuados: p de $\chi^{2}$ y de la prueba de Bollen-Stine $>$ $0,01, \chi 2 / g \mid \leq 3$, FD y PNCP $\leq 1 / 3$ del valor correspondiente al modelo independiente, RMSEA y RMS SR $\leq 0,08, \mathrm{GFI} \geq 0,85$ y AGFI, NFI y $\mathrm{CFI} \geq 0,80^{(33,34)}$.
Se calculó la parsimonia de los modelos por la razón de parsimonia de JamesMulaik-Brett. Los valores de parsimonia de 0 a ,19 se consideraron muy bajos, de 0,20 a 0,39 bajos, de 0,40 a 0,59 medianos, de 0,60 a 0,79 altos y de 0,80 a 1 muy altos $^{(33)}$.

La consistencia interna de los factores de primer y segundo orden se estimó por el coeficiente alfa de Cronbach $(\alpha)$; se consideraron valores altos aquéllos $\geq 0,70$, adecuados $\geq 0,60$ y bajos $<0,60^{(35)}$.

Una vez determinada la configuración de los factores de primer y segundo orden de la escala, se crearon las puntuaciones por suma simple de ítems. Se describió sus distribuciones de estas puntuaciones por medio de estadísticos de tendencia central (media y mediana), de variación (desviación típica, valor mínimo y valor máximo) y forma de la distribución (sesgo y curtosis). El ajuste de la distribución a una curva normal se contrastó por la prueba de Kolmogorov-Smirnov $\left(Z_{\mathrm{K}-\mathrm{S}}\right)$ y de Lilliefors (menos conservadora con la hipótesis nula de normalidad y con mayor potencia).

Para interpretar los valores de las escalas de respuestas psicológicas de duelo ante la pérdida de la salud se utilizaron los cinco valores discretos y enunciados de respuesta a los ítems. A tal fin se dividió la puntuación suma de cada factor por el número de ítems sumados. De este modo se obtuvo un rango continuo, cuyo valor mínimo potencial coincide con el valor más bajo de respuesta al ítem (1) y su valor máximo potencial coincide con el valor más alto de respuesta al ítem (5). A continuación, se dividió este rango continuo en cinco intervalos de amplitud constante ([valor máximo - valor mínimo] / número de valores discretos de respuesta al ítem $=$ amplitud del intervalo $=(5-1) / 5=0,8)$. De este modo se pudo hacer corresponder los 5 intervalos con amplitud constante de 0,80 ordenados de menos a más con los 5 valores discretos de respuesta a los ítems (referentes a fre- 
cuencia de respuesta): de 1 a 1,79= valor discreto 1 "nunca", de 1,80 a 2,59 = valor discreto 2 "pocas veces", de 2,60 a 3,39= valor discreto 3 "a veces" y de 3,40 a 4,19 = valor discreto 4 "casi siempre" y 4,20 a 5 = valor discreto 5 "siempre".

Las comparaciones de medias se realizaron por la prueba $\mathrm{t}$ de Student para muestras emparejadas y análisis de varianza de medidas repetidas (ANOVA). Se comprobó el supuesto de esfericidad del ANOVA (independencia de residuos) por medio de la prueba de Mauchly y se aplicó la corrección de Greenhouse-Geisser al incumplirse el supuesto.

\section{RESULTADOS}

\section{Estructura factorial y consistencia interna}

Se aplicó el análisis paralelo de Horn a los 43 ítems seleccionados. El punto de intersección entre la curva de sedimentación de los datos observados y la curva de sedimentación de los datos creados (100 muestras) correspondiente al percentil 95 fue 1,33. Cinco autovalores observados quedaron por encima de este punto de intersección, por lo que el número de factores por el criterio de Horn fue 5. Debido a que no se obtuvo claramente la solución esperada desde las 5 fases de Kübler-Ross (negación, ira, pacto/negociación, depresión y aceptación), se extrajeron también 6 factores con la expectativa que apareciese un sexto factor de fe/esperanza en la recuperación, como en el estudio de Moral y Miaja $^{(27)}$.

El ítem 50 mostró problemas en la saturación en ambas soluciones (con 5 y 6 factores) y al no agruparse en el factor esperado de negación se eliminó. En la solución de 6 factores, los ítems 4, 9, 38 y 48 también mostraron problemas al no agruparse en el factor esperado de depresión, por lo que también fueron eliminados. De este modo, la escala quedó reducida a 38 ítems. Al aplicar el análisis paralelo de Horn a los 38 ítems, el punto de intersección fue 1. Seis autovalores observados quedaron por encima de este punto de intersección, por lo que el número de factores por el criterio de Horn fue 6, lo que coincide con la expectativa(27).

Al extraer los 6 factores se explicó el $46,46 \%$ de la varianza total. Tras la rotación, se definió un primer factor que agrupó los 10 ítems de aceptación con consistencia interna alta $(\alpha=0,85)$. El segundo factor agrupó los 7 ítems de promesas/negociación con un Ser Supremo con consistencia interna alta $(\alpha=0,83)$. El tercer factor agrupó los 6 ítems de ira con consistencia interna alta $(\alpha=0,82)$. El cuarto factor agrupó los 7 ítems de negación con consistencia interna alta $(\alpha=0,72)$. El quinto factor agrupó los 4 ítems de fe/esperanza en la recuperación con consistencia interna alta $(\alpha=0,80)$. El sexto factor agrupó los 4 ítems de depresión con consistencia interna alta $(\alpha=0,73)$ (véase la tabla 1$)$.

Se estimó el ajuste y significación de parámetros del modelo de 6 factores correlacionados que proporcionó el AFE por medio de AFC. La curtosis multivariada de Mardia estandarizada de los 38 ítems fue 19,72, lo que reflejó desviación de la normalidad multivariada.

De las 15 correlaciones entre los 6 factores, se retuvieron las 7 significativas (véase la figura 1). El modelo tuvo una parsimonia muy alta $(R P=0,94)$. La bondad de ajuste se rechazó por la prueba ji-cuadrado $(\chi 2[658, \quad \mathrm{~N}=120]=1.057,62$, $p<0,01)$; no obstante, el cociente entre el estadístico ji-cuadrado y sus grados de libertad mostró buen ajuste $(\chi 2 / g \mid=1,61)$. La prueba de muestreo repetitivo de BollenStine con la extracción de 2.000 muestras también indicó buen ajuste $(p=248 / 2.000$ $=0,12$ ). Todos los parámetros fueron significativos tanto por la estimación ML como por el método de percentiles libres de sesgo. Los índices $\left.\mathrm{FD}=8,89<\left[\mathrm{FD}_{\mathrm{Ml}}=20,36\right]\right)$, 


\section{Tabla 1. Matriz de configuraciones}

\begin{tabular}{|c|c|c|c|c|c|c|}
\hline \multirow{2}{*}{ Ítems } & \multicolumn{6}{|c|}{ Componentes } \\
\hline & 1 & 2 & 3 & 4 & 5 & 6 \\
\hline 61 Aceptar la enfermedad, me hace sentir más tranquila(0). & 0,75 & & & & & \\
\hline 10 Aceptar la enfermedad me permite estar bien. & 0,69 & & & & & \\
\hline 65 Aceptar la enfermedad, me brinda bienestar. & 0,69 & & & & & \\
\hline 24 Estoy aprendiendo a vivir con la enfermedad. & 0,63 & & & & & \\
\hline 5 Aceptar la enfermedad le da un sentido positivo a mi vida. & 0,61 & & & & & \\
\hline 34 Acepto el hecho de tener la enfermedad. & 0,60 & & & & & \\
\hline 59 Pienso que hay algo bueno que aprender de la enfermedad. & 0,47 & & & & & \\
\hline 19 Me he adaptado a los cambios que involucra la enfermedad. & 0,46 & & & & $-0,35$ & \\
\hline 44 Tomo las cosas como son. & 0,36 & & & $-0,30$ & & \\
\hline $29 \mathrm{Al}$ aceptar la enfermedad, siento que me quiero más. & 0,35 & & & & & \\
\hline 22 Me siento mejor al realizar promesas o súplicas a un Ser Supremo. & & 0,76 & & & & \\
\hline 12 Negociar con un Ser Supremo me da fuerzas. & & 0,71 & & & & \\
\hline 3 Realizo promesas o súplicas a un Ser Supremo con la intención de tener un presente más favorable. & & 0,70 & & & & \\
\hline 8 Busco una alianza con un Ser Supremo para que me cure. & & 0,52 & & & 0,30 & \\
\hline 52 Realizo promesas u ofrecimientos esperando una curación. & & 0,49 & & & & \\
\hline 27 Prometo ser mejor persona, si me recupero. & & 0,42 & & & & \\
\hline 17 Prometo portarme mejor para mejorar mi salud. & & 0,36 & & & & \\
\hline 41 Siento mucho coraje por tener la enfermedad. & & & 0,88 & & & \\
\hline 36 Me enojo con conmigo misma(o) por tener la enfermedad. & & & 0,72 & & & \\
\hline 21 Actuó de manera agresiva con las demás personas; por ejemplo, les insulto. & & & 0,68 & & & \\
\hline 46 Pienso por qué a mí. & & & 0,58 & $-0,35$ & & \\
\hline 51 Siento que es injusto tener la enfermedad. & & & 0,53 & $-0,34$ & & \\
\hline 31 Me enojo con la vida por tener la enfermedad. & & & 0,41 & & & \\
\hline 64 No puedo creer que tenga esta enfermedad. & & & & $-0,59$ & & \\
\hline 60 Me siento mejor al negar la enfermedad. & & 0,30 & & $-0,44$ & & \\
\hline 45 Me resulta tan dolorosa la realidad que prefiero negarla. & & & 0,32 & $-0,43$ & & \\
\hline 55 Niego la enfermedad por miedo a que me tengan lástima. & & & & $-0,40$ & & \\
\hline 6 Niego completamente que estoy enferma(0). & & & & $-0,39$ & & \\
\hline 62 No quiero enterarme de lo que me sucede. & & & & $-0,39$ & & \\
\hline 15 No necesito cuidarme, pues no estoy enfermo. & & & & $-0,36$ & & \\
\hline 57 Pienso que mi fe me ayudará a tener un mejor futuro. & & & & & 0,73 & \\
\hline 37 Pienso que mi fe mejorará mi salud. & & & & & 0,67 & \\
\hline 42 Pienso que mi fe me ayudará a salir adelante. & & & & & 0,66 & \\
\hline 32 La fe me ayuda a pensar positivamente. & & & & & 0,54 & \\
\hline 43 No tengo ganas de hacer nada. & & & & & & 0,71 \\
\hline 53 Siento que se me acaban las fuerzas. & & & & & & 0,65 \\
\hline 28 Tengo ganas de estar todo el día acostada(o). & & & & & & 0,55 \\
\hline 58 He perdido el interés en casi todas las actividades de mi vida. & & & & & & 0,37 \\
\hline
\end{tabular}

Método de extracción: Ejes Principales. Método de extracción: Oblimin. La rotación convergió en 15 iteraciones. 
$\left.\mathrm{PNCP}=3,36<\left[\mathrm{PNCP}_{\mathrm{Ml}}=14,45\right]\right)$ y $\mathrm{RMS}$ $E A=0,07$ ( $p<0,01$ de que RMSEA $\leq 0,05$ ) reflejaron un ajuste adecuado. No obstante, los índices GFI=0,69, AGFI=0,65, $\mathrm{NFI}=0,56, \mathrm{CFI}=0,77$ y RMS SR=0,11 mostraron mal ajuste.

Debido a la altísima parsimonia del modelo no resulta realista reproducir con exactitud los 722 momentos a partir de los cuales se estimaron los parámetros, de ahí estos índices de ajuste. El modelo de 6 factores cuenta con consistencia interna alta en todos sus factores, se fundamenta por el análisis paralelo de Horn y se sostiene por algunos de los índices de bondad de ajuste global robustos ( $p$ de Bollen-Stine, ఒ2/gl y RMS EA).

Se calcularon las puntuaciones de los factores de primer orden por el método de regresión y desde su matriz de correlaciones se extrajeron los factores de segundo orden. El número de factores de segun- do orden fue dos por el criterio de Kaiser. Con dos factores se explicó $37,90 \%$ de la varianza total. Tras la rotación oblicua, se definió un primer factor configurado por depresión e ira con cargas positivas y por aceptación y negación con cargas negativas. Por su contenido se denominó reacción de afecto negativo ante la enfermedad. La consistencia interna de los 27 ítems que integran las escalas de depresión (4 ítem directos), ira (6 ítems directos), aceptación (10 ítems invertidos) y negación (7 ítems invertidos) fue alta $(\alpha=0,71)$. No obstante, si se calculase el coeficiente alfa de Cronbach con los 7 ítems de negación directos su valor subiría a 0,87. El segundo factor quedó configurado por promesas/negociación con un Ser Supremo y fe/esperanza en la recuperación, ambos con cargas positivas. El factor de negación presentó una carga negativa y mayor que 0,30 en este factor de segundo orden. Por

Figura 1. Modelo estandarizado de 6 factores correlacionados con 38 ítems estimado por ML.

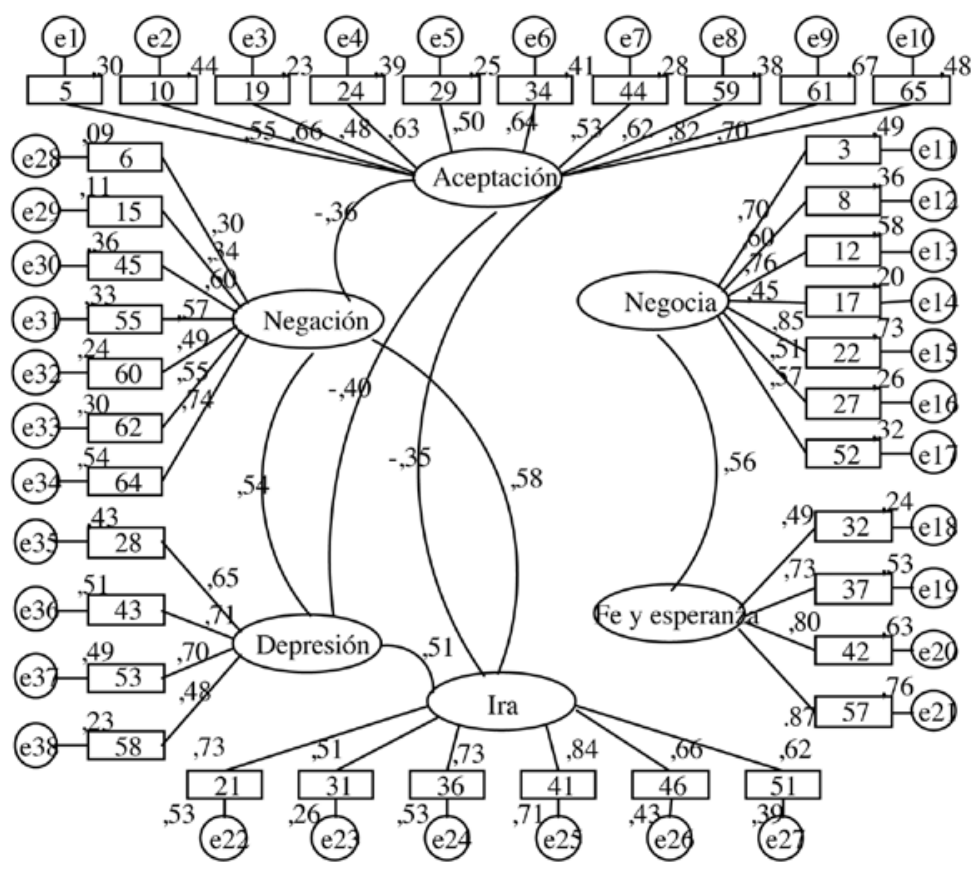


su contenido se denominó de actitud positiva ante la enfermedad. La consistencia interna de los 11 ítems de promesas/negociación y fe/esperanza fue alta $(\alpha=0,85)$. Si se incluyen los ítems de negación invertidos, el valor del coeficiente alfa de Cronbach disminuiría bastante $(\alpha=0,68)$, y si se incluyesen directos disminuye ligeramente $(\alpha=0,83)$. Ambos factores tuvieron una correlación nula $(r<0,01, p=0,99)$ (véase la tabla 2).

Por AFC se contrastó un modelo de dos factores independientes (véase la figura 2). El factor de reacción de afecto negativo ante la enfermedad con 4 indicadores (puntuaciones de los factores de primer orden de depresión, ira, aceptación y negación) y el factor de actitud positiva ante la enfermedad con 3 indicadores (puntuaciones de los factores de primer orden de promesas/negociación, fe/esperanza y negación). El valor de la curtosis de Mardia estandarizado $(14,07)$, lo que reflejó desviación de la normalidad multivariada. Todos los parámetros fueron significativos tanto por la estimación $\mathrm{ML}$ como por la estimación de percentiles libres de sesgo. La bondad de ajuste se mantuvo por la prueba de Bollen-Stine: el ajuste $(p=796 / 2 \cdot 000=0,40)$. También se mantuvo por la prueba ji-cuadrado $(\chi 2$ [8, $N=120]=12,94, p=0,11)$. Los demás índices reflejaron un ajuste de bueno ( $\chi 2 /$ $\mathrm{gl}=1,62, \mathrm{GFl}=0,97, \mathrm{AGFl}=0,91, \mathrm{CFl}=0,94$,
$\mathrm{FD}=0,11 \quad\left[\mathrm{FD}_{\mathrm{MI}}=0,83\right], \mathrm{PNCP}=0,04[\mathrm{PN}-$ $\left.\mathrm{CP}_{M I}=0,71\right]$ y RMSEA $=0,07$ [ $p=0,27$ de que RMSEA $\leq 0,05])$ a adecuados (NFI=0,87 y RMS SR $=0,07)$. Por lo tanto, la bondad de ajuste de este modelo bidimensional de segundo orden fue buena. Si se añadiese la correlación entre los dos factores, ésta no sería significativa $(r=0,15, p=.10)$.

Las puntuaciones de los factores de segundo orden se crearon por suma simple de ítems. Se decidió incluir los 7 ítems de negación sólo en el factor de segundo orden de reacción de afecto negativo porque quedarían repetitivos si se incluyesen también en el factor de segundo orden de actitud positiva y generarían una correlación significativa y positiva entre ambos factores $(r=0,34, p<0,01)$, cuando la correlación directa no es congruente con la interpretación dada a los factores y su significación no es congruente con los resultados del AFE y AFC. Además, se decidió incluirlos como ítems directos, al igual que los ítems de depresión e ira, por los resultados del análisis de consistencia interna (aumentan de forma importante la consistencia interna del factor de reacción de afecto negativo como ítems directos cuando disminuyen la consistencia interna del factor de actitud positiva, ya sea como ítems inversos o directos), por ser más congruente con la interpretación dada al factor de reacción de afecto negativo (más ira, más depresión,

\section{Tabla 2. Matrices de configuraciones y estructural de los 6 factores de primer orden (puntuaciones obtenidas por el método de regresión)}

\begin{tabular}{ccccc}
\hline Factores & \multicolumn{2}{c}{ Configuraciones } & \multicolumn{2}{c}{ Estructural } \\
\cline { 2 - 4 } De primer orden & $\mathrm{F} 1$ & $\mathrm{~F} 2$ & $\mathrm{~F} 1$ & $\mathrm{~F} 2$ \\
\hline Depresión & 0,69 & & 0,69 & \\
Ira & 0,67 & & 0,67 & \\
Aceptación & $-0,49$ & $-0,49$ & $-0,34$ \\
Negación & $-0,36$ & $-0,34$ & $-0,36$ & 0,67 \\
Promesas/negociación & & 0,67 & & 0,60 \\
Fe/esperanza & & 0,60 & & \\
\hline
\end{tabular}

Método de extracción: Ejes principales. Rotación: Oblimin. Convergió en 5 iteraciones. 
Figura 2. Modelo estandarizado de 2 factores de segundo orden estimado por ML.

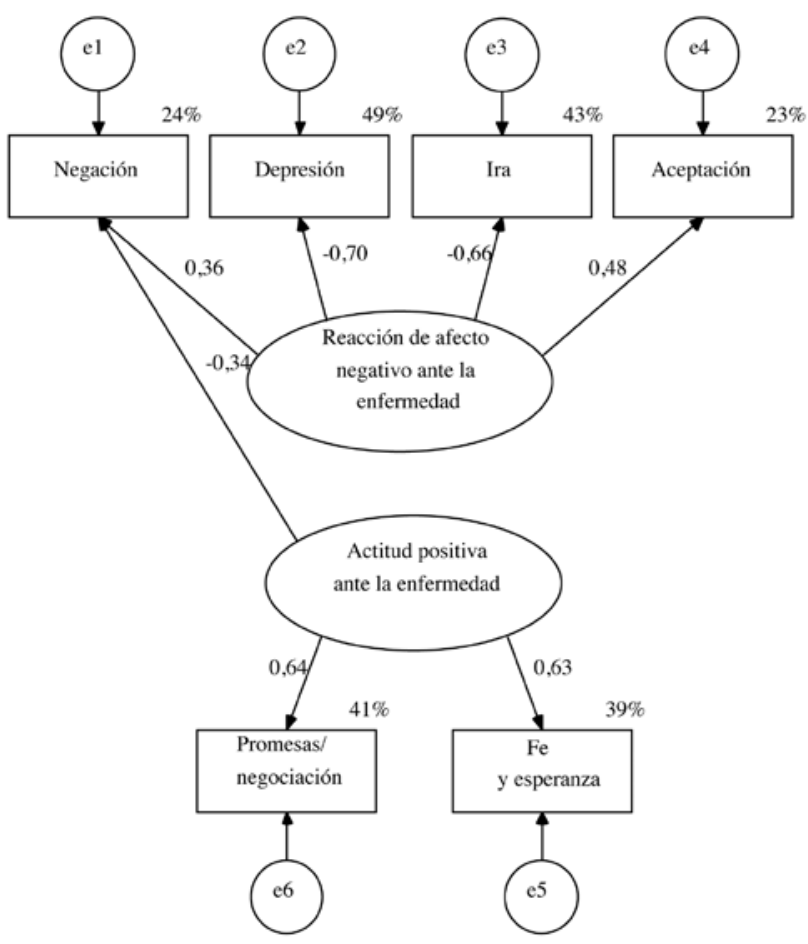

más negación y menos aceptación) y por reproducir la independiencia de factores $(r=0,02, p=0,83)$, obtenida tanto por AFE como por AFC.

El factor de segundo orden de reacción de afecto negativo ante la enfermedad se definió por la suma de los 4 ítems directos de depresión, 6 ítems directos de ira, 10 ítems inversos de aceptación y 7 ítems directos de negación. El factor de segundo orden de actitud positiva ante la enfermedad se definió por la suma de los 7 ítems directos de promesas/negociación y los 4 ítems directos de fe/esperanza.

Distribución de los 6 factores de primer orden y 2 de segundo orden

Ninguno de los factores de primer orden se ajustó a una curva normal. Los factores de negación y depresión mostraron distribuciones con asimetría po- sitiva y mesocurtosis $(C=0,10 ; E T=0,44$, y $\mathrm{C}=-0,29, \mathrm{ET}=0,44$, respectivamente). El factor de ira mostró una distribución con asimetría positiva y apuntamiento $(\mathrm{C}=5,26$; $\mathrm{ET}=0,44)$. Los factores de aceptación y promesas/negociación mostraron una distribución con asimetría negativa y mesocurtosis $(C=-0,07$; $E T=0,44$, y $C=-$ 0,65 ; $\mathrm{ET}=0,44$, respectivamente). El factor de fe/esperanza mostró una distribución con asimetría negativa y apuntamiento $(\mathrm{C}=6,87 ; \mathrm{ET}=0,44)$ (véase Tabla 3).

La distribución de la actitud positiva tuvo un rango de 1 a 5, mostró sesgo hacia los valores altos $(S=1,03 ; E T=0,22)$ y no se ajusto a una curva normal (Kolmogorov-Smirnov: $Z_{K-S}=2,60 ; p=0,01$; Lilliefors: $\left.D_{a b s}=0,15 ; p<0,01\right)$. La distribución de la reacción de afecto negativo, a pesar de su rango más limitado (de 1 a 3,26) que la distribución de actitud positiva, se ajustó a una curva normal por la prue- 
ba de Kolmogorov-Smirnov $\left(Z_{\mathrm{K}-\mathrm{s}}=1,19\right.$; $p=0,12)$, pero no por la prueba de Lilliefors $\left(D_{a b s}=0,11 ; p<0,01\right)$ (véase la tabla 3 ).

Frecuencia de expresión de las respuestas de duelo evaluadas

Se dividió la media de los seis factores de primer orden y los dos factores de segundo orden por sus correspondientes números de ítems, obteniéndose un rango continuo de 1 a 5 . A continuación se dividió este rango continuo en 5 intervalos de amplitud constante para hacerlos corresponder con los 5 valores discretos de respuesta al ítem (de 1 "nunca" a 5 "siempre") e interpretar los valores en correspondencia con las etiquetas de respuesta al ítem.

La media del factor de negación fue de 1,82 , lo que correspondió al segundo intervalo de puntuaciones continuas (de 1,80 a 2,59), esto es, al valor discreto 2 "pocas veces"; al igual que en el factor de depresión $(1,86)$. La media del factor de ira fue de 1,49, lo que correspondió al primer intervalo de puntuaciones continuas (de $1 \mathrm{a}$
$1,79)$, esto es, al valor discreto 1 "nunca". La media del factor de promesas/negociación fue de 3,72, lo que correspondió al cuarto intervalo de puntuaciones continuas (de 3,40 a 4,19), esto es, al valor discreto 4 "casi siempre". La media del factor de fe/esperanza fue de 4,62, lo que correspondió al quinto intervalo de puntuaciones continuas (de 4,20 a 5), esto es, al valor discreto 5 "siempre", al igual que en el factor de aceptación $(4,23)$ (véase la tabla 4 y la figura 3 ).

La mayoría de las respuestas en los factores de ira, depresión y negación correspondieron al rango de 1 a 2,59, esto es, a respuestas de nunca o pocas veces. El 91\% de las participantes dieron respuestas dentro de este rango en el factor de ira, $88 \%$ en el factor de depresión y $82 \%$ en el factor de negación. La mayoría de las respuestas en los factores de promesas/ negociación, fe/esperanza y aceptación correspondieron al rango de 3,40 a 5 , esto es, a respuestas de casi siempre o siempre. El $92 \%$ de las participantes dieron respuestas dentro de este rango en el factor de fe/esperanza, $86 \%$ en el fac-

\section{Tabla 3. Consistencia interna, descripción de las distribuciones y normalidad de la escala RPD-PS-38}

\begin{tabular}{|c|c|c|c|c|c|c|c|c|c|c|c|c|}
\hline \multirow{2}{*}{$\begin{array}{l}\text { RPD- } \\
\text { PS38 }\end{array}$} & \multicolumn{2}{|c|}{ Consistencia } & \multicolumn{7}{|c|}{ Descriptivos de la distribución } & \multicolumn{3}{|c|}{ Normalidad } \\
\hline & $\begin{array}{l}\text { No. } \\
\text { ítems }\end{array}$ & $\alpha$ & Min & Max & M & Mdn & DT & S & $\mathrm{C}$ & $Z_{\mathrm{K}-\mathrm{S}}$ & $\mathrm{p}$ & $p^{*}$ \\
\hline Negac. & 7 & 0,72 & 1 & 4 & 1,82 & 1,57 & 0,82 & 0,98 & 0,10 & 1,769 & $<0,01$ & $<0,01$ \\
\hline Ira & 6 & 0,82 & 1 & 4 & 1,49 & 1,33 & 0,72 & 2,25 & 5,26 & 2,69 & $<0,01$ & $<0,01$ \\
\hline Pro/ne & 7 & 0,83 & 1 & 5 & 3,72 & 4,00 & 1,08 & $-0,64$ & $-0,65$ & 1,50 & 0,02 & $<0,01$ \\
\hline Fe/esp & 4 & 0,80 & 1 & 5 & 4,62 & 5,00 & 0,73 & $-2,48$ & 6, & 3,80 & $<0,01$ & $<0,01$ \\
\hline Depre. & 4 & 0,73 & I & 4 & 1,86 & 1,50 & 0,85 & 0,83 & $-0,29$ & 2,06 & $<0,01$ & $<0,01$ \\
\hline Acept. & 10 & 0,85 & 2 & 5 & 4,23 & 4,40 & 0,73 & $-0,81$ & $-0,07$ & 1,59 & 0,01 & $<0,01$ \\
\hline RANE & 27 & 0,87 & 1 & 3,26 & 1,74 & 1,65 & 0,55 & 0,88 & 0,16 & 1,19 & 0,12 & $<0,01$ \\
\hline APE & 11 & 0,85 & 1 & 5 & 4,05 & 4,27 & 0,85 & $-1,03$ & 0,71 & 2,60 & 0,01 & $<0,01$ \\
\hline
\end{tabular}

RANE = Reacción de afecto negativo ante la enfermedad $=($ depresión + ira + negación + aceptación con ítems invertidos $) / 27 . \mathrm{APE}=$ Actitud positiva ante la enfermedad $=($ Promesas $/$ negociación + Fe/esperanza $) / 11$. Descriptivos de la distribución: Min = valor mínimo, $M a x=$ valor máximo, $M=$ media aritmética, $M d n=$ mediana, DT = desviación típica, $S=$ sesgo $(E T S=0,22)$ y $C=$ curtosis $(E T C=0,44)$. Normalidad: $Z_{K-S}$ : Valor estandarizado de la diferencia máxima absoluta, $\mathrm{p}=$ probabilidad del estadístico $Z_{\mathrm{K}-\mathrm{S},} \mathrm{p}^{*}=$ probabilidad de la diferencia máxima absoluta por la tablas de Lilliefors. 
Figura 3. Diagrama de medias de las respuestas psicológicas de duelo ante la pérdida de la salud.

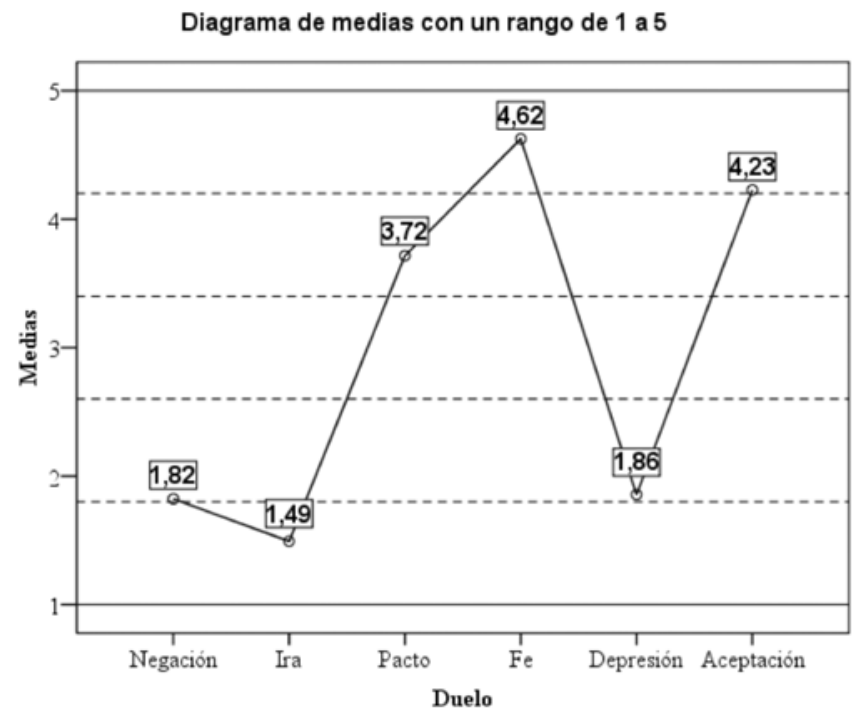

tor de aceptación y $66 \%$ en el factor de promesas/negociación (véase la tabla 4).

La media del factor de segundo orden de reacción de afecto negativo fue de 1,74 , lo que correspondió al primer intervalo de puntuaciones continuas (de $1 \mathrm{a}$ 1,79), esto es, al valor discreto 1 "nunca". La media del factor de segundo orden de actitud positiva fue de 4,05, lo que correspondió al cuarto intervalo de puntuaciones continuas (de 3,40 a 4,19), esto es, al valor discreto 4 "casi siempre" (véase la tabla 4 y la figura 4).

El 91\% de las participantes dieron respuesta dentro del rango de 1 a 2.59 (nunca o pocas veces) en el factor de reacción de afecto negativo y el $78 \%$ de las participantes dieron respuesta de 3,40 a 5 (casi siempre o siempre) en el factor de actitud positiva (véase la tabla 4).

\section{Tabla 4. Distribución de las puntuaciones de los factores de primer y segundo orden en un rango continuo y homogéneo}

\begin{tabular}{|c|c|c|c|c|c|c|c|c|c|c|c|c|c|c|c|c|}
\hline \multirow[t]{2}{*}{ Valores } & \multicolumn{2}{|c|}{ Negación } & \multicolumn{2}{|r|}{$\mathrm{a}$} & \multicolumn{2}{|c|}{$\begin{array}{c}\text { Promesas } \\
\text { Negociación }\end{array}$} & \multicolumn{2}{|c|}{ FE } & \multicolumn{2}{|c|}{ Depresión } & \multicolumn{2}{|c|}{$\begin{array}{l}\text { Acep- } \\
\text { tación }\end{array}$} & \multicolumn{2}{|c|}{ RANE } & \multicolumn{2}{|c|}{ APE } \\
\hline & $f$ & $\%$ & $f$ & $\%$ & $f$ & $\%$ & $f$ & $\%$ & $f$ & $\%$ & $f$ & $\%$ & $f$ & $\%$ & $f$ & $\%$ \\
\hline$[1$, & 72 & 60,0 & 96 & 80,0 & 6 & 5 & 1 & 0 & 72 & & & 0,8 & 74 & 61,7 & 2 & 1,7 \\
\hline$[1,80$, & 26 & 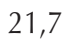 & 13 & 10,8 & $1 \varepsilon$ & 50 & 2 & 1,7 & & & 0 & 0 & 35 & 29,2 & 0 & 5,0 \\
\hline$[2,60,3,39]$ & 15 & 12,5 & 7 & 58 & 17 & 14,2 & 7 & 8 & . & 15,0 & 16 & 13,3 & 11 & 9,2 & 19 & 15,8 \\
\hline$[3,40$, & 6 & 5,0 & 2 & 17 & 29 & 24,2 & 13 & 10,8 & & & 30 & 25,0 & 0 & 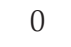 & 29 & 24,2 \\
\hline$[4,20,5]$ & 1 & 0,8 & 2 & 1,7 & 50 & 41,7 & 97 & 80,8 & 1 & 0,8 & 73 & 60,8 & 0 & 0 & 64 & 53,3 \\
\hline
\end{tabular}

Valores: Nunca $=[1,1,79]$, Pocas veces $=[1,80,2,59]$, A veces $=[2,60,3,39]$, Casi siempre $=[3,40,4,19]$, Siempre $=[4,20,5]$. RANE $=$ Reacción de afecto negativo ante la enfermedad $=($ depresión + ira + negación + aceptación con ítems invertidos)/27. APE $=$ Actitud positiva ante la enfermedad $=$ (Promesas/negociación $+\mathrm{Fe} /$ esperanza)/11. FE $=$ Fe y esperanza. 
Figura 4. Diagrama de medias de los dos factores de segundo orden de respuestas psicológicas de duelo ante la pérdida de la salud.

Diagrama de medias con un rango de 1 a 5

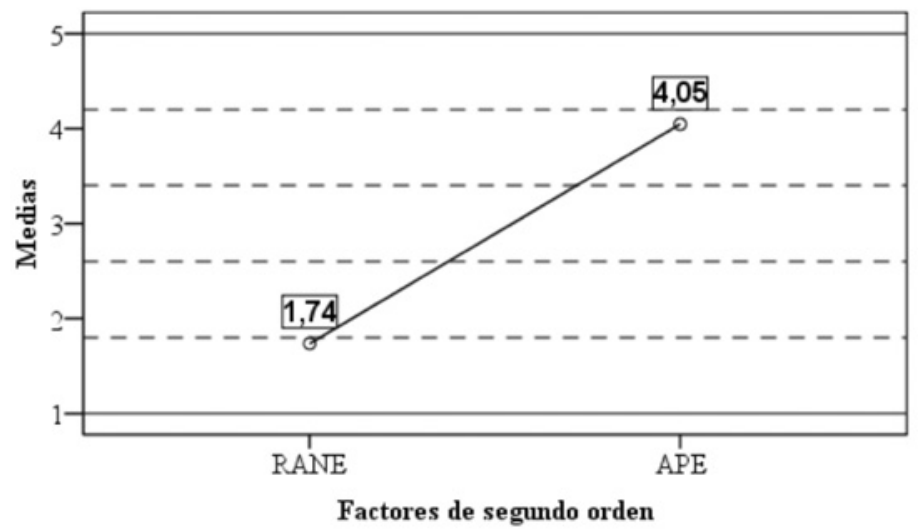

RANE $=$ Reacción de afecto negativo ante la enfermedad $=($ depresión + ira + negación + aceptación con ítems invertidos $) / 27 . \mathrm{APE}=$ Actitud positiva ante la enfermedad $=($ Promesas $/$ negociación + Fe/esperanza $) / 11$.

\section{Comparación de medias entre los factores}

Las medias de los 6 factores de primer orden fueron estadísticamente diferenciales (efectos intraparticipantes: $\mathrm{F}[3,71$, $441,09]=385,05, \mathrm{p}<0,01$; con la corrección de Greenhouse-Geisser, siendo el valor $\varepsilon=0,74$, al no asumirse el supuesto de esfericidad con base en la prueba Mauchly: $\mathrm{W}=0,44, \chi 2[14, \mathrm{~N}=$ $120]=96,90, p<0,01)$. Al hacer comparaciones por pares de medias, hubo diferencia significativa en 14 de las 15 comparaciones con una $p<0,01$. Las medias de los factores de negación ( $M$ $=1,82,95 \%$ IC: $1,67,1,97)$ y depresión $(M=1,86,95 \%$ IC: $1,70,2,01)$ fueron estadísticamente equivalentes $(\mathrm{t}[119]=$ $-0,39, p=0,70)$.

Las medias de los dos factores de segundo orden fueron estadísticamente diferenciales $(\mathrm{t}[119]=25,22, p<0,01)$. La media de la actitud positiva ante la enfermedad ( $M=4,05)$ fue significativamente mayor que la media de reacción de afecto negativo ante la enfermedad $(M=1,74)$.

\section{DISCUSIÓN}

En relación con el primer objetivo del estudio (determinar la estructura factorial de la escala FD-66 reducida a 43 ítems), se confirmó la expectativa de un modelo de seis factores correlacionados, el cual fue propuesto por Moral y Miaja ${ }^{(27)}$ desde en un análisis previo de la escala FD-66 $6^{(15)}$ en base a modelos unidimensionales para cada una de las 5 fases del modelo de Kübler-Ross ${ }^{(16)}$. Así, se obtuvo un factor para cada una de las 5 fases del duelo descritas por Kübler-Ross ${ }^{(16)}$ (negación, ira, promeses/negociación, depresión y aceptación) más el factor de fe/esperanza en la recuperación.

A partir de los seis factores de primer orden correlacionados se definió, por análisis factorial exploratorio y confirmatorio, un modelo de dos factores de segundo orden independientes. Por una parte, se definió el factor de segundo orden reacción de afecto negativo ante la enfermedad por la suma de los ítems directos de depresión, ira y negación y los ítems inversos 
de aceptación (falta de aceptación). Este factor refleja una actitud negativa, pasiva o que huye del problema (negación y falta de aceptación), Ilena de afectos negativos (ira y depresión). Por otra parte, se definió el factor de segundo orden de actitud positiva ante la enfermedad por la suma de los ítems directos de promesas/negociación y fe/esperanza. Este factor refleja un afrontamiento enfocado hacia la recuperación con apoyo en creencias religiosas. El modelo de dos factores independientes del presente estudio se asemeja al modelo de dos factores de emociones propuesto por Watson $^{(36)}$ : emociones positivas (alegría, optimismo, confianza) y emociones negativas (ansiedad, tristeza, ira), así como al modelo de dos estilos de afrontamiento ${ }^{(37)}$ : activo, constructivo o centrado en el problema (reevaluación positiva, búsqueda de apoyo social, solución de problemas) y estilo pasivo, negativo o centrado en la emoción (evitación, autofocalización negativa, irritabilidad). Debe mencionarse que el afrontamiento basado en la religión dentro de los estudios realizados en México aparece en la dimensión de afrontamiento constructivo ${ }^{(38,39)}$, lo que es concordante con el factor de segundo orden de actitud positiva del presente estudio. A su vez, el modelo de dos factores independientes de la presente investigación muestra similitud con un modelo propuesto anteriormente para el afrontamiento de situaciones de pérdida de seres queridos ${ }^{(40)}$, en el cual se distingue un factor de afrontamiento enfocado hacia la perdida (Ileno de emoción negativa al aferrarse a la persona perdida) y de afrontamiento enfocado hacia la recuperación o superación de la pérdida (con un afrontamiento más activo).

En relación con el segundo objetivo también se confirmó la expectativa. Los valores de consistencia interna de los seis factores de primer orden y los dos factores de segundo orden fueron altos, mayores que 0,70 , pero menores que 0,90 , lo que es propio de escalas multidimensionales, cuando valores iguales o mayores que 0,90 son propios de escalas unidimensionales $^{(35)}$.

El tercer objetivo del estudio era describir las distribuciones de los factores con la expectativa de normalidad. La distribución de los seis factores de primer orden y el factor de segundo orden de actitud positiva ante la enfermedad no se ajustaron a una curva normal, e incluso el factor de reacción de afecto negativo se desvió de la normalidad al aplicar la prueba de Kolmogorov-Smirnov-Lilliefors, por lo que no se cumplió la expectativa. Los factores de negación, ira y depresión presentaron asimetría positiva; este sesgo hacia los valores de baja frecuencia es propio de las distribuciones de rasgos patológicos o con mucho estigma social, ante los cuales la mayoría de las personas reportan carecer del aspecto enfermo-desadaptativo o desvalorizado socialmente. Los factores de aceptación, promesas/negociación, fe/ esperanza, y actitud positiva ante la enfermedad mostraron asimetría negativa; este sesgo hacia los valores de alta frecuencia es propio de las distribuciones de características básicas de adaptación (que casi todos tienen) o rasgos socialmente muy deseados, ante los cuales la mayoría de las personas reportan poseer el aspecto sano-adaptativo y deseado socialmente ${ }^{(28)}$. La falta de normalidad indican que las respuestas psicológicas, en estas pacientes oncológicas con una media de más de año transcurrido desde el diagnóstico, se asemeja al de la población general, probablemente debido a que completaron con éxito el proceso de duelo.

Los niveles promedios de las respuestas psicológicas de duelo que predominaron fueron fe/esperanza, y la aceptación de la enfermedad. En su estudio, Barragán y Almanza-Rodríguez ${ }^{(41)}$ hallaron que la fe $y$ las plegarias, y la esperanza en la mejoría de la enfermedad fueron las estrategias de 
afrontamiento del dolor predominantes en una muestra de pacientes con cáncer. Maciejewski et al. ${ }^{(9)}$ también encontraron que la aceptación de la pérdida fue el componente más frecuentemente reportado por los deudos. La ira ante la enfermedad fue la respuesta psicológica menos reportada por las pacientes con cáncer de este estudio. Precisamente, Maciejewski et al.(9) encontraron que la ira fue el componente menos reportado en los tres momentos del estudio: 6, 11 y 19 meses después de la muerte de su ser querido y que la depresión era más reportada que la ira en los tres momentos de aplicación. Así se confirmaron las expectativas en relación con los objetivos 4 y 5 .

\section{LIMITACIONES}

Como limitaciones del estudio debe mencionarse que el diseño fue no experimental transversal, de ahí que no se pueden hacer inferencias de causalidad y sólo se habla de correlatos. También este estudio tiene como limitación el carecer de una muestra poblacional, habiéndose realizado en una muestra incidental de mujeres con cáncer bajo tratamiento oncológico, por lo que los resultados deben manejarse como hipótesis para futuras investigaciones en esta población y otras afines. Inicialmente se pretendía obtener una muestra de al menos 200 participantes, la mitad mujeres y la mitad hombres. Sin embargo, resultó imposible obtener una muestra de 100 hombres, debido a que en los centros en los cuales se aplicaron los cuestionarios y en los cuales se contaba con permiso de las autoridades, acudían mayoritariamente mujeres.

\section{CONCLUSIONES}

Tras la selección final de los ítems, con base en sus propiedades psicométricas de consistencia interna y peso factorial, la es- cala de Respuestas Psicológicas de Duelo ante la Pérdida de la Salud (RPD-PDS-38) quedó conformada por 38 ítems. Conforme con la expectativa, presentó una estructura de seis factores de primer orden correlacionados (negación, ira, promesas/ negociación, fe/esperanza, depresión y aceptación), y dos factores de segundo orden independientes (reacción de afecto negativo ante la enfermedad y actitud positiva ante la enfermedad). El factor de negación quedó conformado por 7 indicadores (ítems: 1, 7, 13, 19, 25, 29 y 33), el de ira por 6 indicadores (ítems: 2, 8, 14, 20, 26 y 30), el de promesas/negociación con un Ser Supremo por 7 indicadores (ítems: 3, 9, $15,21,27,31$ y 35), el fe/esperanza por 4 indicadores (ítems: 4, 10, 16 y 22), el de depresión por 4 indicadores (ítems: 5, 11,17 y 23) y el factor de aceptación por 10 indicadores (ítems: 6, 12, 18, 24, 28, $32,34,36,37$ y 38). En el anexo puede verse la correspondencia entre los ítems de RPD-PDS-38 y FD-66.

El modelo de seis factores correlacionados tuvo un ajuste a los datos de adecuado a malo. Se sostiene claramente por el análisis paralelo de Horn, los valores de consistencia interna e interpretación de los factores rotados. El modelo de dos factores independientes de segundo orden mostró un ajuste de bueno a adecuado. Debe señalarse que el ajuste a los datos está matemáticamente planteado como una reproducción exacta (con residuos mínimos) de la matriz de varianza-covarianzas de los datos observados. Con las puntuaciones factoriales se calcula la matriz de varianzacovarianzas reproducida y al hacer la diferencia entre estas dos matrices se obtienen los residuos que deberían ser nulos en caso de buen ajuste. En la medida que es mayor el número de ítems, se hace muy difícil o no realista lograr residuos muy pequeños y por consiguiente obtener buenos índices de ajuste. Así, el modelo de 6 factores con los 38 ítems tiene problema de ajuste, esto es, 
reproducción exacta de las varianza-covarianzas originales, pero no así el modelo de 2 factores con 6 indicadores (puntuaciones de los factores de primer orden).

Conforme con la expectativa, los valores de consistencia interna para los seis factores de primer orden y los dos factores de segundo orden fueron altos.

La distribución de los seis factores de primer y los dos factores de segundo orden no se ajustaron a una curva normal, por lo que deben ser baremados por medio de puntuaciones de percentil. Quizá en las primeras semanas tras el diagnóstico sí podría confirmarse la expectativa de normalidad, pero no en pacientes que llevan meses o más de un año viviendo con la enfermedad.

Conforme con la expectativa, los niveles promedios de las respuestas psicológicas de duelo ante la pérdida de la salud que predominaron en estas pacientes con cáncer fueron fe/esperanza y la aceptación. Las respuestas psicológicas menos frecuentes fueron ira, depresión y negación. Intermedia quedó promesas/negociación con un Ser Supremo.

\section{SUGERENCIAS}

Se recomienda utilizar la escala RPDPS-38 para conocer como están elaborando el proceso del duelo por el que están pasando los pacientes con cáncer. De esta manera los profesionales de la salud que trabajan o acompañan a los pacientes en su proceso de enfermedad puedan identificar a las personas que podrían tener problemas al afrontar su duelo, e intervenir en el trabajo de duelo para disminuir los efectos de los factores de riesgo y fortalecer los factores protectores, para así prevenir problemas médicos y psicológicos adicionales en las personas con cáncer.

Se sugiere, en futuros estudios, obtener una muestra equivalente de sexos, para poder hacer un contraste multigrupo de la estructura factorial de primer (6 facto- res correlacionados) y segundo orden (dos dimensiones independientes) de la escala RPD-PS-38, y una muestra probabilística que estimar los baremos (percentiles). Estos estudios se podrían realizar en pacientes con cáncer u otras enfermedades crónicas en México u otros países.

Agradecimientos: Este trabajo fue realizado con el apoyo de la beca doctoral otorgada a la primera autora por el CONACYT. Se agradece a las pacientes y a las instituciones que permitieron el acceso a la muestra: Cruz Rosa, A.B.P., Desafío del Noreste, A.C., Posada del Peregrino de Caritas de Monterrey, A.B.P., Clínica 0-19, Clínica Opción Oncología, Asociación Mexicana Contra el Cáncer de Mama, A.C. de la Fundación CIM*ab y el grupo de autoayuda Mujeres con Cáncer.

\section{REFERENCIAS BIBLIOGRÁFICAS}

1. Artigas J. Implicaciones psicológicas y sociales de las epilepsias del adolescente. Rev Neurol 1999;28:43-9.

2. Díaz VE. Sexualidad, cuerpo y duelo: experiencia clínica con mujeres diagnosticadas con cáncer ginecológico o de mama. Pensamiento Psicológico 2010;7:155-60.

3. Tizón J. Pérdida, pena, duelo: vivencias, investigación y asistencia. Barcelona: Paidós, 2004.

4. Worden JW. El tratamiento del duelo: asesoramiento psicológico y terapia ( $2^{\mathrm{a}} \mathrm{ed}$.). Barcelona: Paidós, 2010.

5. Payás A. Las tareas del duelo: psicoterapia de duelo desde un modelo integrativorelacional. Barcelona: Paidós, 2010.

6. Blanco L, Librada S, Rocafort J, Cabo R, Galea T, Alonso ME. Perfil del cuidador principal del enfermo en situación terminal y análisis del riesgo de desarrollar duelo patológico. Med Paliat 2007;14:1-5.

7. Cabodevilla I. Las pérdidas y sus duelos. Anales Sist San Navarra 2007;30:163-76. 10.4321/S1137-66272007000600012 
8. Lobb EA, Kristjanson LJ, Aoun SM, Monterosso L, Halkett GKB, Davies A. Predictors of complicated grief: A systematic review of empirical studies. Death Stud 2010;34:673-98. Doi: 10.1080/07481187.2010.496686.

9. Maciejewski PK, Zhang B, Block SD, Prigerson HG. An empirical examination of the stage theory of grief. JAMA 2007;297:71624. Doi:10.1001/jama.297.7.716

10. Neimeyer RA. Lessons of loss. Guide to coping (2nd. ed.). New York, NY: Brunner Routledge, 2002.

11. Sánchez R, Gutiérrez C, Valencia JA. La muerte de un ser querido: validez y confiabilidad de una medida de regulación emocional. Revista Mexicana de Investigación en Psicología 2011;3(1):72-84.

12. Tomarken A, Holland J, Schachter S, Vanderwerker L, Zuckerman E, Nelson C, et al. Factors of complicated grief predeath in caregivers of cancer patients. Psychooncology 2008;17:105-11. Doi: 10.1002/pon.1188.

13. Sanders CM, Mauger PA, Strong PN. A manual for the Grief Experience Inventory. Blowing Rock, NC: The Center for the Study of Separation and Loss, 1985.

14. Faschingbauer TR, De Vaul RA, Zissok S. Development of the Texas Inventory of Grief. Am J Psychiat 1977;134, 696-8.

15. Miaja M, Moral J. El significado psicológico de las cinco fases del duelo propuestas por Kübler-Ross mediante las redes semánticas naturales. Psicooncología 2013;10:109-30. Doi: 10.5209/ rev_PSIC.2013.v10.41951.

16. Kübler-Ross E. On death and dying. New York, NY: Macmillan, 1969.

17. Isla P, Moncho J, Guasch O, Torras A. Proceso de adaptación a la diabetes mellitus tipo 1 (DM1). Concordancia con las etapas del proceso de duelo descrito por Kübler-Ross. Endocrinología y Nutrición 2008;55:78-83.

18. Greer S. The management of denial in cancer patients. Oncol 1992;6:33-6.
19. Kreitler S. Denial in cancer patients. Cancer Invest 1999;17:514-34.

20. Rabinowitz T, Peirson R. "Nothing is wrong, doctor": Understanding and managing denial in patients with cancer. Cancer Invest 2006;24:68-76. Doi: 10.1080/07357900500449678.

21. Sandín B. Papel de las emociones negativas en el trastorno cardiovascular: un análisis crítico. Rev Psicopatol Psicol Clin 2002;7:1-18.

22. De León V, Cuetos C. Tanatología: Una perspectiva distinta de la muerte. Boletín Médico 2004;5:13-9.

23. Llantá MC, Massip C, Martínez Y. La significación de la esperanza en el paciente oncológico. Revista Electrónica Medicina, Salud y Sociedad 2012; 2(3):15575. Consultado 09/04/2014. Disponible en: http://www.medicinasaludysociedad. com/site/images/stories/2_3/May12EsperanzaPacientesOncologicos.pdf

24. Pinquart $M$, Duberstein PR. Depression and cancer mortality: Ameta-analysis. Psychol Med 2010;40:1797-810. Doi:10.1017/S0033291709992285.

25. Satin JR, Linden W, Phillips MJ. Depression as a predictor of disease progression and mortality in cancer patients: A metaanalysis. Cancer 2009;115:5349-61. Doi: 10.1002/cncr.24561.

26. Moral J, Valdez JL, Alvarado BG. Instrumentación métrica del concepto de paz. Daena: International Journal of Good Conscience 2011;6:11-39.

27. Moral J, Miaja M. Contraste del modelo de las 5 fases de duelo de Kübler-Ross en mujeres con cáncer. Pensamiento Psicológico 2014; en prensa.

28. Sartori R. The bell curve in psychological research and practice: myth or reality? Qual Quant 2006;40:407-18.

29. Sánchez R, Dos-Santos MA. Cáncer de mama, pobreza y salud mental: respuesta emocional a la enfermedad en mujeres de camadas populares. Rev Latino-Am Enfermagem 2007;15:786-91. Doi: 10.1590/ S0104-11692007000700012. 
30. Gaviria AM, Vinaccia S, Riveros MF, Quiceno JM. Calidad de vida relacionada con la salud, afrontamiento del estrés y emociones negativas en pacientes con cáncer en tratamiento quimioterapéutico. Psicol Caribe 2007;20:50-75.

31. Moral J, Martínez J. Reacción ante el diagnóstico de cáncer en un hijo: estrés y afrontamiento. Psicol Salud 2009;19:189-96.

32. Sociedad Mexicana de Psicología. Código ético del psicólogo ( $4^{\mathrm{a}}$ ed.). México, DF: Editorial Trillas, 2007.

33. Kline RB. Principles and practice of structural equation modeling (3a ed.). New York, NY: The Guilford Press, 2010.

34. Moral J. Análisis factorial confirmatorio. En: Landero R, González MT., editors. Estadística con SPSS y metodología de la investigación. México, DF: Trillas, 2006; p.445-528.

35. Cronbach LJ, Shavelson RJ. My current thoughts on coefficient alpha and successor procedures. EducPsychol Meas 2004;64:391418. Doi:10.1177/0013164404266386
36. Watson D. Mood and temperament. New York: Guilford Press, 2000.

37. Folkman S. The Oxford handbook of stress, health, and coping. New York: Oxford University Press, 2011.

38. Moral J, Miaja M. Validación del cuestionario de afrontamiento del estrés en dos muestras de personas seropositivas y población general. Ansiedad Estrés 2012;18:15-29.

39. González MT, Landero R. Cuestionario de afrontamiento del estrés (CAE): validación en una muestra mexicana. Rev Psicopatol Psicol Clin 2007;12: 189-98.

40. Stroebe $M$, Schut $H$. The dual process model of coping with bereavement: Rationale and description. Death Stud 1999; 23:197-224. Doi:0.1080/074811899201046

41. Barragán JA, Almanza-Rodríguez G. Valoración de estrategias de afrontamiento, a nivel ambulatorio, del dolor crónico en personas con cáncer. Aquichan 2013;13:322-35. 


\section{ANEXO 1. Escala Respuestas Psicológicas de Duelo ante la Pérdida de Salud (RPD-PS-38)}

Instrucciones: Encierre en un círculo con qué frecuencia experimenta estas acciones, sentimientos y pensamientos en relación a su proceso de enfermedad.

1

Nunca
2

Pocas veces
3
4

Casi siempre
5

Siempre

\begin{tabular}{|c|c|c|c|c|c|c|}
\hline & Ítem & \multicolumn{5}{|c|}{ Frecuencia } \\
\hline 1 & 6. Niego completamente que estoy enferma(o). & 1 & 2 & 3 & 4 & 5 \\
\hline 2 & 21. Actuó de manera agresiva con las demás personas; por ejemplo, les insulto. & 1 & 2 & 3 & 4 & 5 \\
\hline 3 & $\begin{array}{l}\text { 3. Realizo promesas o súplicas a un Ser Supremo con la intención de tener un } \\
\text { presente más favorable. }\end{array}$ & 1 & 2 & 3 & 4 & 5 \\
\hline 4 & 32. La fe me ayuda a pensar positivamente. & 1 & 2 & 3 & 4 & 5 \\
\hline 5 & 28. Tengo ganas de estar todo el día acostada(o). & 1 & 2 & 3 & 4 & 5 \\
\hline 6 & 5. Aceptar la enfermedad le da un sentido positivo a mi vida. & 1 & 2 & 3 & 4 & 5 \\
\hline 7 & 15. No necesito cuidarme, pues no estoy enfermo. & 1 & 2 & 3 & 4 & 5 \\
\hline 8 & 31. Me enojo con la vida por tener la enfermedad. & 1 & 2 & 3 & 4 & 5 \\
\hline 9 & 8. Busco una alianza con un Ser Supremo para que me cure. & 1 & 2 & 3 & 4 & 5 \\
\hline 10 & 37. Pienso que mi fe mejorará mi salud. & 1 & 2 & 3 & 4 & 5 \\
\hline 11 & 43. No tengo ganas de hacer nada. & 1 & 2 & 3 & 4 & 5 \\
\hline 12 & 10. Aceptar la enfermedad me permite estar bien. & 1 & 2 & 3 & 4 & 5 \\
\hline 13 & 45. Me resulta tan dolorosa la realidad que prefiero negarla. & 1 & 2 & 3 & 4 & 5 \\
\hline 14 & 36. Me enojo con conmigo misma(o) por tener la enfermedad. & 1 & 2 & 3 & 4 & 5 \\
\hline 15 & 17. Prometo portarme mejor para mejorar mi salud. & 1 & 2 & 3 & 4 & 5 \\
\hline 16 & 42. Pienso que mi fe me ayudará a salir adelante. & 1 & 2 & 3 & 4 & 5 \\
\hline 17 & 53. Siento que se me acaban las fuerzas. & 1 & 2 & 3 & 4 & 5 \\
\hline 18 & 19. Me he adaptado a los cambios que involucra la enfermedad. & 1 & 2 & 3 & 4 & 5 \\
\hline 19 & 55. Niego la enfermedad por miedo a que me tengan lástima. & 1 & 2 & 3 & 4 & 5 \\
\hline 20 & 41. Siento mucho coraje por tener la enfermedad. & 1 & 2 & 3 & 4 & 5 \\
\hline 21 & 12. Negociar con un Ser Supremo me da fuerzas. & 1 & 2 & 3 & 4 & 5 \\
\hline 22 & 57. Pienso que mi fe me ayudará a tener un mejor futuro. & 1 & 2 & 3 & 4 & 5 \\
\hline 23 & 58. He perdido el interés en casi todas las actividades de mi vida. & 1 & 2 & 3 & 4 & 5 \\
\hline 24 & 24. Estoy aprendiendo a vivir con la enfermedad. & 1 & 2 & 3 & 4 & 5 \\
\hline 25 & 60. Me siento mejor al negar la enfermedad. & 1 & 2 & 3 & 4 & 5 \\
\hline 26 & 46. Pienso por qué a mí. & 1 & 2 & 3 & 4 & 5 \\
\hline 27 & 22. Me siento mejor al realizar promesas o súplicas a un Ser Supremo. & 1 & 2 & 3 & 4 & 5 \\
\hline 28 & 29. Al aceptar la enfermedad, siento que me quiero más. & 1 & 2 & 3 & 4 & 5 \\
\hline 29 & 62. No quiero enterarme de lo que me sucede. & 1 & 2 & 3 & 4 & 5 \\
\hline 30 & 51. Siento que es injusto tener la enfermedad. & 1 & 2 & 3 & 4 & 5 \\
\hline 31 & 27. Prometo ser mejor persona, si me recupero. & 1 & 2 & 3 & 4 & 5 \\
\hline 32 & 34. Acepto el hecho de tener la enfermedad. & 1 & 2 & 3 & 4 & 5 \\
\hline 33 & 64. No puedo creer que tenga esta enfermedad. & 1 & 2 & 3 & 4 & 5 \\
\hline 34 & 44. Tomo las cosas como son. & 1 & 2 & 3 & 4 & 5 \\
\hline 35 & 52. Realizo promesas u ofrecimientos esperando una curación. & 1 & 2 & 3 & 4 & 5 \\
\hline 36 & 59. Pienso que hay algo bueno que aprender de la enfermedad. & 1 & 2 & 3 & 4 & 5 \\
\hline 37 & 61. Aceptar la enfermedad, me hace sentir más tranquila(o). & 1 & 2 & 3 & 4 & 5 \\
\hline 38 & 65. Aceptar la enfermedad, me brinda bienestar. & 1 & 2 & 3 & 4 & 5 \\
\hline
\end{tabular}

